\title{
Análise ecossistêmica da serra do mar paranaense, porção área de especial interesse turístico do Marumbi
}

As áreas protegidas objetivam a conservação da biodiversidade. Analisando relações bióticas e abióticas da Área de Especial Interesse Turístico do Marumbi (AEIT), situada na serra do mar paranaense e que contempla cinco Parques Estaduais em ambiente montanhoso sob o domínio da Floresta Ombrófila Densa, buscam-se indicadores de efetividade ecológica. Através da construção e interpretação cartográfica, do georreferenciamento, do intercruzamento dos aspectos geológicos, dos geomorfológicos, dos hidrográficos, dos vegetacionais, da altimetria, da declividade e perímetros das unidades de conservação (UC), revelaram a distribuição de 3.703 nascentes em 66.000 hectares (ha), média de uma a cada 18,02 ha. A maior parte na Montana (600 a $1200 \mathrm{~m} \mathrm{s.n.m.)} \mathrm{com} \mathrm{53 \%} \mathrm{e} \mathrm{na} \mathrm{Submontana} \mathrm{(} 30$ a $600 \mathrm{~m}$ s.n.m) com $26,5 \%$. Diferentemente da bibliografia consultada que indicava abundância de nascentes nas cimeiras; o resultado foi $6,7 \%$ na Altomontana e $1,8 \%$ nos Campos de Altitude (acima de $1200 \mathrm{~m}$ s.n.m). No cruzamento de nascentes com domínios geológicos, o granito apresenta $57,7 \%$ de ocorrência e o complexo migmatitico $35,2 \%$ sendo este na relação unidade/área mais representativo. Apenas $20,4 \%$ das nascentes estão em unidades de conservação (ucs) de proteção integral analisadas.

Palavras-chave: Áreas protegidas; Aspectos geológicos; Floresta Ombrófila Densa.

\section{Ecosystem analysis of the Serra do Mar Paraná, portion of Marumbi's area of special tourist interest}

\begin{abstract}
Protected areas aim to conserve biodiversity. Analyzing biotic and abiotic relations of the Marumbi Area of Special Tourist Interest (AEIT), located in the Serra do Mar Paraná State and which includes five State Parks in a mountainous environment under the domain of Dense Ombrophilous Forest, we seek indicators of ecological effectiveness. Through the construction and cartographic interpretation, georeferencing, intercrossing of geological, geomorphological, hydrographic, vegetative, elevation, slope and perimeter of protected areas (UC), the distribution of 3,703 springs over 66,000 hectares (ha), average of one every 18.02 ha. Most in Montana (600 to $1200 \mathrm{~m} \mathrm{s.n.m.)} \mathrm{with} 53 \%$ and Submontana ( 30 to $600 \mathrm{~m} \mathrm{s.n.m)} \mathrm{with} 26.5 \%$. Unlike the bibliography consulted that indicated abundance of springs at the summits; The result was $6.7 \%$ in Altomontana and $1.8 \%$ in Altitude Fields (over $1200 \mathrm{~m} \mathrm{s.n.m).} \mathrm{In} \mathrm{the} \mathrm{intersection} \mathrm{of} \mathrm{springs} \mathrm{with} \mathrm{geological} \mathrm{domains,} \mathrm{granite}$ presents $57.7 \%$ of occurrence and the migmatitic complex $35.2 \%$ being the most representative unit/area ratio. Only $20.4 \%$ of the springs are in full protection protected areas (ucs) analyzed.
\end{abstract}

Keywords: Protected areas; Geological aspects; Dense Ombrophilous Forest.

Topic: Ciências Florestais

Reviewed anonymously in the process of blind peer.
Received: 12/08/2019

Approved: 27/09/2019
Maurício Savi (D)

Faculdade Bagozzi, Brasil

http://lattes.cnpq.br/7117433638079076

http://orcid.org/0000-0002-8709-2002

savimauricio@hotmail.com

Jaçanan Eloisa de Freitas Milani (iD

Universidade Federal do Mato Grosso, Brasil

http://lattes.cnpq.br/1248478849153563

http://orcid.org/0000-0002-4831-2551

jacanan.milani@gmail.com

Barbara Gabriele de Souza Nogueira (iD

Universidade Federal do Paraná, Brasil

http://lattes.cnpq.br/7268779325599940

http://orcid.org/0000-0001-7517-4003

barbaragsnogueira@gmail.com
Joana Caroline de Freitas Rosin (iD

Universidade Federal do Paraná, Brasil

http://lattes.cnpq.br/8196238045124432

http://orcid.org/0000-0002-0734-5883

joana.frosin@gmail.com

Carlos Vellozo Roderjan (iD

Universidade Federal do Paraná, Brasil

http://lattes.cnpq.br/6063964023661857

http://orcid.org/0000-0002-1872-5355

roderjan@ufpr.br
Referencing this:

SAVI, M.; MILANI, J. E. F.; NOGUEIRA, B. G. S.; ROSIN, J. C. F.; RODERJAN, C. V.. Análise ecossistêmica da serra do mar paranaense, porção área de especial interesse turístico do Marumbi. Revista Ibero Americana de Ciências Ambientais, v.10, n.5, p.36-46, 2019. DOI: http://doi.org/10.6008/CBPC2179-6858.2019.005.0004 


\section{INTRODUÇÃO}

A necessidade de proteger, conhecer e usufruir a natureza é aspiração da humanidade. A Estratégia Mundial para a Conservação da Biodiversidade (WRI et al., 1992), estabelece como prioridade à conservação in situ, estruturalmente formada por áreas protegidas, onde a ecologia, complementada por outras áreas do conhecimento, buscam a fundamentação cientifica e técnica para a proteção de paisagens, espécies e funções ecológicas, entre outros aspectos.

A ciência não apontou melhor solução para a conservação da natureza que o estabelecimento de parques e reservas. A forma de realizar este objetivo deve ser indagada e aprimorada. Afinal, critérios relativos ao tamanho, ao design, a riqueza ecológica, a distribuição de populações, as comunidades biológicas, as espécies ameaçadas, as endêmicas, as vulnerabilidades e pressões antrópicas, são indicativos para seleção de áreas, e categorias de conservação.

Sobre biodiversidade e ações prioritárias conservacionistas, pesquisas de Myres et al. (2000) estabelecem como orientação o conceito de hotspots: regiões com maiores concentrações em riqueza de espécies e níveis elevados de pressão e destruição de hábitat, nas quais ações protetivas destas áreas poderiam salvaguardar maior riqueza de espécies por unidade área.

Contudo, ao seguirmos este modelo, áreas com menor diversidade biológica, mas estrutural e funcionalmente dependentes das conexões ecossistêmicas de sua área e entorno como mangues, restingas, campos naturais ou altitudinais (SCARANO, 2002), entre outros ecossistemas, não seriam prioritárias. E apesar da conexão trófica entre ecossistemas com mecanismos biológicos e químicos que asseguram a continuidade e diversidade da vida, estariam num nível de inferior importância e consequentemente de menor proteção.

Neste contexto, a busca da conservação da natureza, segundo Figueiredo et al. (2006), segue dois objetivos: representatividade biológica para que áreas protegidas possam garantir a proteção de amostra substancial da biodiversidade e condições para persistência e viabilidade das populações protegidas. Os aspectos bióticos são prioritários na criação e planejamento de áreas protegidas contemporâneas. Para compreender e assegurar sistemas ecológicos significa incluir, avaliar e analisar as propriedades abióticas conjuntamente, na compreensão do padrão e organização da paisagem, aonde populações e comunidades serão resultados das condições físicas e químicas que o ambiente proporciona.

A representatividade dos ecossistemas nos atuais 'modelos de conservação' não assegura serviços naturais, como oportunidades de educação, espiritualidade, recreação, controle hídrico, regulação climática, contenção de erosão e polinização, entre outros (CONSTANZA et al., 1997). Estes serviços da natureza não atingem significativa parcela das sociedades. No Paraná, o conjunto de áreas protegidas não permite a proteção adequada de seus ecossistemas, praticamente todas as regiões do estado (excluindo a Serra do Mar) apresentam quadro de degradação alarmante, e contínuo.

Este trabalho busca a compreensão e avaliação da conservação do sistema ecológico de parte da Serra do Mar, seguindo as relações de dependência ambiental, entre os quais: o relevo, o clima, os rios, os 
solos, e as plantas, de forma integrada e interligada. Sendo determinantes, fundamentos técnicos, científicos e legais na proteção da natureza em representatividade quali-quantitativa. Os indicativos bióticos e abióticos analisados podem assegurar orientações para a criação unidades de conservação e o estabelecimento de perímetros que contemplem com maior eficácia premissas das funções ecossistêmicas do ambiente e por consequente, oportunizar a conservação da vida silvestre e suas interações ambientais em longo prazo.

\section{MATERIAIS E MÉTODOS}

A AEIT do Marumbi tem 66 mil hectares com um conjunto de parques inseridos em seu perímetro: Parque Estadual Pico do Marumbi, da Graciosa, do Pau-Ôco e Roberto Ribas Lange, sendo que outras ucs foram criadas ou sobrepostas posteriormente como é o caso do Parque Estadual Pico Paraná. Contudo em acordar com a Lei № 9.985/00 que estabelece o Sistema Nacional de Unidades de Conservação a categoria da AEIT - Marumbi, deveria se adequar por similaridade a Área de Proteção Ambiental, destaca-se que esta região é reconhecida como Reserva da Biosfera, e inclusa, em 1999, na Lista dos Sítios do Patrimônio Mundial Natural (Reservas do Sudeste da Mata Atlântica) (UNESCO, 2000).

A Serra do Mar é um conjunto de escarpas festonadas com cerca de 1.000 km de extensão, largura de 5 a 10 km e desnível médio de 1.000 m, atingindo o limite máximo, nesta no Paraná, de 1969 m no Pico Paraná. Na região afloram abundantes granitos neoproterozóicos (c.a. $600 \mathrm{Ma}$ ) formados durante o processo de consolidação do embasamento da Plataforma Sul-Americana, granitos gerados pelo relaxamento crustal após as colisões que geraram a megacontinente Gondwana. A feição de Serra está relacionada à separação continental entre a América do Sul e África iniciada há cerca de 130 milhões de anos com o surgimento do Oceano Atlântico. No processo de separação continental ocorreu um amplo soerguimento em toda a borda leste do continente sul americano no sudeste do Brasil. Este soerguimento ocasionou levantamentos e rebaixamentos de grandes blocos por falhas geológicas (MINEROPAR 2001). De forma geral, na área de estudo podem ser individualizados os domínios geológicos constituídos por terrenos sustentados pelas rochas do embasamento cristalino (gnaisses e migmatitos), por rochas graníticas, rochas intrusivas mesozóicas (diques de diabásio e diorito) e depósitos sedimentares recentes (PARANÁ, 2003).

O complexo serrano da área de estudo constitui uma barreira natural entre planície litorânea e o primeiro planalto, apresentando ventos regulares que sopram de sudeste. A umidade destes ventos condensa na sua vertente oriental, desencadeando chuvas orográficas em suas encostas, onde são registrados os mais elevados índices pluviométricos do Paraná. A classificação climática regional corresponde ao tipo de clima subtropical úmido mesotérmico (PIRES et al., 2005).

A vegetação da área da AEIT compreende diferentes tipologias, sendo dominante a Floresta Ombrófila Densa, variando de 30 a 1.800 metros de altitude (formações Submontana, Montana e Altomontana e Campos Altitudinais). Para a construção da base cartográfica da área de estudo (AEITMarumbi) utilizou-se os seguintes níveis de informação: Curvas de nível, pontos cotados e hidrografia: em escala 1:50.000, produzidos pela Diretoria de Serviços Geográficos do Exército Brasileiro (DSG, 1989), referentes às cartas de Mapa Índice (MI) 2842-4, 2843-1, 2843-2, 2843-3, 2843-4, 2857-2 e 2858-1; 
Vegetação e geologia: escala 1:50.000, produzidos pelo Programa de Proteção à Floresta Atlântica/Secretaria Estadual do Meio Ambiente e Recursos Hídricos do Paraná (PARANÁ, 2005); Unidades de conservação: produzidos pela Secretaria Estadual do Meio Ambiente e Recursos Hídricos do Paraná (SEMA).

Todos os níveis de informação estavam em formato Shapefile, compatível com sistemas de geoprocessamento. No apoio aos mapeamentos, foram utilizadas imagens do satélite SPOT 5, com data de passagem no ano de 2005. Para o ajuste, o contraste e o realce das imagens foi realizado processamento digital a partir de imagens georreferenciadas, compondo um mosaico para o recobrimento da área de estudo. O recorte da imagem e dos vetores foi realizado utilizando-se o polígono do limite da Área de Relevante Interesse Ecológico (AEIT) do Marumbi por meio do software ArcGis 9.0 (ESRI, 2004).

As informações referentes ao relevo da área de estudo foram obtidas por meio da geração de um Modelo Digital do Terreno - MDT, pelo método TIN (Triangulated Irregular Networks), do módulo 3D Analist do ArcGIS 9.0 (ESRI, 2004). O método TIN é definido com uma malha de elementos triangulares que modela o terreno (KUMLER, 1994) e é considerado o mais adequado para a inclusão de feições topográficas estruturais (FELGUEIRAS, 2000). O modelo foi produzido com base nas curvas de nível, nos pontos cotados e na hidrografia (breaklines) extraídos das cartas geradas pela DSG (1989). As nascentes existentes na área de estudo foram digitalizadas individualmente, com o auxílio do software ArcGIS 9.0 (ESRI, 2004), tendo como base as informações de hidrografia e de relevo.

\section{RESULTADOS}

Ao salvaguardarmos regiões expressivas em diversidade biológica através de unidades de conservação, é necessário contemplar processos físiográficos de modelagem dos meios naturais, que serão fatores de influência na paisagem, na riqueza e abundância de espécies e ecossistemas. Os designs geométricos artificiais dos perímetros das unidades de conservação dificultam a inclusão de variações altitudinais de vegetação, morros e montanhas, a variabilidade geológica, à riqueza dos padrões de drenagem e nascentes, não sendo raro que Ucs deixem fora estes e outros aspectos relevantes, porém próximos ou contíguos de sua área de proteção.

Os dados e informações obtidos oportunizaram a elaboração de planilhas matemáticas e mapas temáticos (hidrografia, geologia e vegetação), sendo estes intercruzados espacialmente e sobrepostos por altimetria, declividade juntamente com os perímetros das unidades de conservação de manejo restrito, as métricas quantitativas das unidades bióticas e abióticas abordadas, e a sobreposição dos dados permitiu informações do meio e organização da bioestrutura da AEIT do Marumbi.

\section{Geologia e geomorfologia}

A área de interesse apresenta duas unidades geológicas predominantes, o complexo ígneo Província Serra do Mar, conjunto composto de uma grande variedade de granitoides pós-colisionais à formação do paleocontinente Gondwana (595-550 Ma), e o Complexo Atuba, unidade composta por gnaissesmigmatíticos gerados no Paleoproterozoico (c.a. 2.0 Ga) (HEILBRON et al., 2008). 
Os maciços graníticos são dominantes na área de estudo com 57\% do total ou 38.203 hectares, representando as regiões escarpadas e com elevadas altitudes. Este espaço granítico forma uma típica 'Serra', aonde as cadeias paralelas de montanhas se organizam predominantemente na direção $60^{\circ} \mathrm{N}$ e $30^{\circ}$ $\mathrm{NE}$, com contrafortes a $45^{\circ} \mathrm{NW}$.

O complexo metamórfico Atuba apresenta menores altitudes e representa 29\% ou 19.468 hectares da área de estudo, sendo delimitado a leste pelos picos mais elevados da Província Serra do Mar, uma das mais destacadas feições orográficas da borda atlântica do continente sul-americano. Ao estabelecer um padrão espacial cartográfico de distribuição hidrológica da área de estudo, as nascentes revelam um sistema de drenagem que esta correlacionada as estruturas geológicas e geomorfológicas. O mapeamento da área de estudo revelou 3.703 nascentes, o que representa a média de uma nascente a cada, 18,02 hectares.

Ao sobrepor os mapas de padrão de nascentes com os domínios litológicos, resultados diferentes das literaturas foram obtidos. Ao comparar as proporcionalidades rochosas e o número de nascentes que apresentam drenagem e distribuição superficial ao relevo, a unidade litológica de maior destaque recai no Complexo Atuba, que representa a proporção de $29 \%$ (19.468 ha) da área de estudo e com $35,2 \%$ (1.305) do total de nascentes. Já o padrão granítico, com 57\% (38.203 ha) da área, responde a 57,7\% (2.128) das nascentes com escoamento superficial, sendo que esta litopologia se divide em três sub-unidades: granito Anhangava com 134 ha e 03 nascentes, o granito Marumbi com 6.976 ha e 437 nascentes e o granito Graciosa, com 31.093 ha e 1.667 nascentes.

As unidades em questão têm diferentes arcabouços litológicos-estruturais. A configuração atual dos gnaisses-migmatíticos, por exemplo, resulta da sobreposição de inúmeros eventos tectônicos. O complexo é a unidade mais antiga, está extremamente deformado pelas variações de pressão e temperatura durante sua complexa história tectônica e apresentam uma assembleia mineralógica mais susceptível a transformações físico-químicas do intemperismo em relação ao granitoides. Portanto o Complexo Atuba tem mais descontinuidades, como falhas e fraturas em seu arranjo estrutural, permitindo, quanto estas estão interconectadas, uma maior permeabilidade e vazão do aquífero.

No relatório da Carta das águas subterrâneas do Paraná (2015) o complexo gnáissico-migmatítico é classificado como produtividade 4 (produtividade geralmente baixa, porém localmente moderada) enquanto as rochas aflorantes nas escarpas e montanhas da Serra do Mar são consideradas como não aquíferos, ou seja, classe 6 de produtividade, pois, o elevado declive compromete a infiltração e consequente recarga do aquífero. É possível observar no mapa potenciométrico das unidades aquíferas do Paraná, que de maneira geral, o sentido do fluxo a oeste, nos altos topográficos da Bacia de Curitiba, quanto a oeste, na escarpa, favorece a infiltração no Complexo.

Segundo Bretanha (2007) as nascentes são um ponto em que o freático emerge na superfície. Dependendo da natureza da recarga e das características de transmissão e armazenamento das unidades litológicas através do qual a água flui, podem ser permanentes (perenes - de fluxo contínuo), sazonais (fluxo apenas na estação chuvosa) ou intermitentes (permanecendo por apenas alguns dias ou horas).

Considerando a alta declividade, extensa cobertura vegetal e maiores taxas de pluviosidade da Serra 
do Mar e consequentemente mais vertentes, logo, essa unidade apresenta uma rede de drenagens temporárias extensa e como resultado um maior número de vertentes. É necessário checar em campo a perenidade das nascentes identificadas para determinação das APPs.

Essas unidades litológicas pertencem a unidade aquífera embasamento cristalino e são classificadas como predominantemente de alta vulnerabilidade a contaminação relatório da Carta das águas subterrâneas do Paraná (2015), processos que pode ser agravado com a retirada de vegetação e desenvolvimento de processos erosivos nas nascentes do rio e/ou pelo assoreamento crescente ao longo dos rios.

As demais litografias ocorrentes na área de estudo, apresentam menor expressividade de área são: magnetita quartizitos, com 6,06 hectares e sem nenhuma nascente inserida em seu domínio litográfico, muscovita - biotita - quartizitos, com 69,5 ha e 6 nascentes, xistos magnesianos anfibolitos parcialmente migmatizados que representam 598,3 hectares com 42 nascentes, os diques de riolitos pórfiro, com 33,15 ha e uma nascente, arcósio-siltitos-argilitos e conglomerados tem 255 hectares e 20 nascentes, os depósitos de talus, com 206 ha abrangem 7 nascentes, já com maior evidencia o complexo granítico gnáissico que ocorre em 1098 hectares e 94 nascentes, os aluviões antigos, com 2.373 hectares e 24 nascentes (Figura 1).

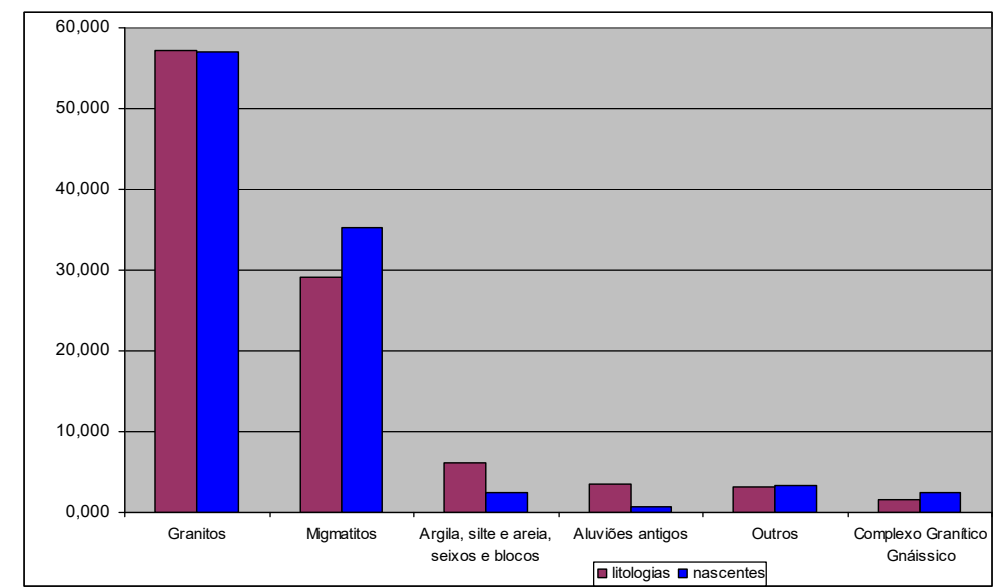

Figura 1: Comparação das tipologias de rochas em relação as nascentes.

\section{Vegetação}

A tipologia vegetacional segue um padrão organizacional relacionado a geomorfologia, a faixas altitudinais, solos e a rede de drenagem. Como conseqüências desses aspectos são encontradas na área de estudo, a partir de 30m s.n.m. (limite altimétrico inferior), as formações Terras Baixas, Submontana, Montana, Altomontana e Aluvial da Floresta Ombrófila Densa, áreas de Floresta Ombrófila Mista na sua vertente oriental, além de Áreas de Refúgios Vegetacionais Altomontanos (campos de altitude e vegetação rupestre) nas suas porções mais elevadas, áreas localizadas de Formações Pioneiras com Influência Flúviolacustre (várzeas) e, por fim, estágio inicial da sucessão vegetal (bracatingal) (Figura 2).

\section{Perfil fitogeográfico esquemático da área de estudo}

Para identificar a proporção dos diferentes tipos de vegetação da área de estudo foi seguida à classificação adotada por Paraná (2002), no mapeamento da Serra do Mar paranaense no Programa de 
Proteção da Floresta Atlântica - Pró-Atlântica. Da sobreposição do perímetro da área da AEIT ao mapeamento do referido programa, obteve-se: F.O.D. das Terras Baixas com 0,9 ha $(0,001 \%)$, FOD Submontana com 21.828 ha (32,6\%), FOD Montana, que é a formação de maior ocorrência, com 32.901 ha $(49,2 \%)$, FOD Altomontana com 4.312,2 ha $(6,4 \%)$, FOD Aluvial, com 26,3 ha $(0,04 \%)$, FOM Montana com 4.377 ha (6,5\%), Refúgios Vegetacionais com 1.461 ha (2,1\%), Formações Pioneiras com 111,9 hectares (2,08 \%) e estágio inicial com 32,3 ha (0,05\%). As áreas desprovidas de vegetação (adensamentos urbanos, solo exposto e corpos d'água) perfizeram um total de $1.393,5$ ha $(2,1 \%)$ na área total da AEIT Marumbi.

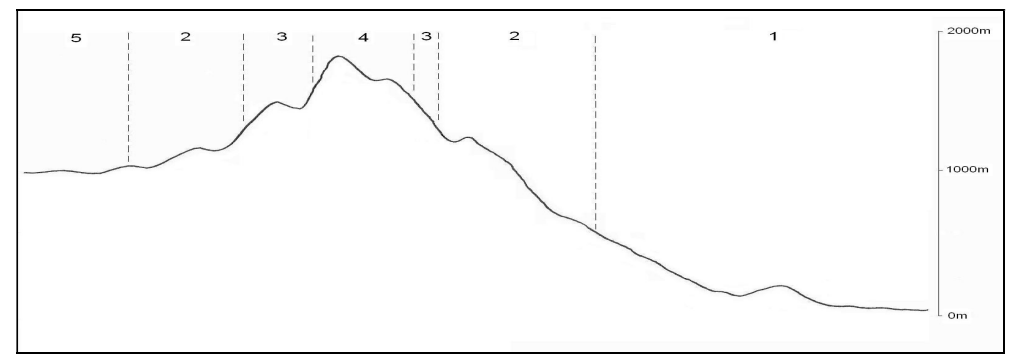

Figura 2: Floresta Ombrófila Densa Submontana; 2- Floresta Ombrófila Densa Montana; 3- Floresta Ombrófila Densa Altomontana; 4- Refúgios Vegetacionais; 5- Contato Floresta Ombrófila Densa/Floresta Ombrófila Mista.

Para compreender a vegetação e sua riqueza de ambientes também é necessário entender a hidrografia. A relação de interdependência entre a flora, fauna e os meios hidrológicos, ainda é constituída de lacunas cientificas para avaliação de sua dimensão e importância. Apesar de evidente, a maioria dos estudos enfoca a relação da floresta com o clima, as vazões dos rios e os possíveis processos erosivos quando consorciado a ações antrópicas.

Neste contexto, o Parque Estadual Pico do Marumbi, protege esta rede hídrica com 516 nascentes (uma a cada 14,9 ha), em mais de 8.745 hectares. O P.E. da Graciosa em seus poucos 758 ha, protege 82 nascentes (uma a cada 13,9 ha), o P.E. Roberto Ribas Lange 121 (uma a cada 23 ha) e o P.E do Pau Oco em seus 880 hectares, uma nascente a cada 22 ha.

\section{Vegetação e Nascentes}

O cruzamento da tipologia vegetacional da AEIT do Marumbi com as nascentes se destaca a Floresta Ombrófila Densa Montana, que abrange faixas altitudinais de 600 a 1.200m s.n.m. Este patamar, com grande extensão e dominialidade territorial, apresenta a maior ocorrência em número absoluto de nascentes com 1.958 , representando o total de $53 \%$.

Outra área de evidência é a Floresta Ombrófila Densa Submontana, situada nas faixas altitudinais de 30 a 600 m s.n.m. Apresenta proporcionalmente menor relação de área com nascentes, seus números são significativos: 981 nascentes ou 26,5\% do total mapeado. Estas duas formações somadas compreendem mais de $70 \%$ da vegetação ocorrente e apresentam $80 \%$ das nascentes da área de estudo.

Contudo as vegetações que dominam os cumes serranos acima dos 1.200 m s.n.m., possuem a função ecológica estratégica na absorção e retenção da pluviosidade e da água atmosférica. Este serviço natural exerce a regulagem e equilíbrio dos períodos com maior umidade na Serra do Mar, considerando a elevada 
média das regiões cimeiras, acima dos $3.000 \mathrm{~mm}$. O controle desta vazão, bem como a liberação da água nos períodos mais secos, permite o equilíbrio dos ecossistemas com o seu meio físico. (Figura 3).

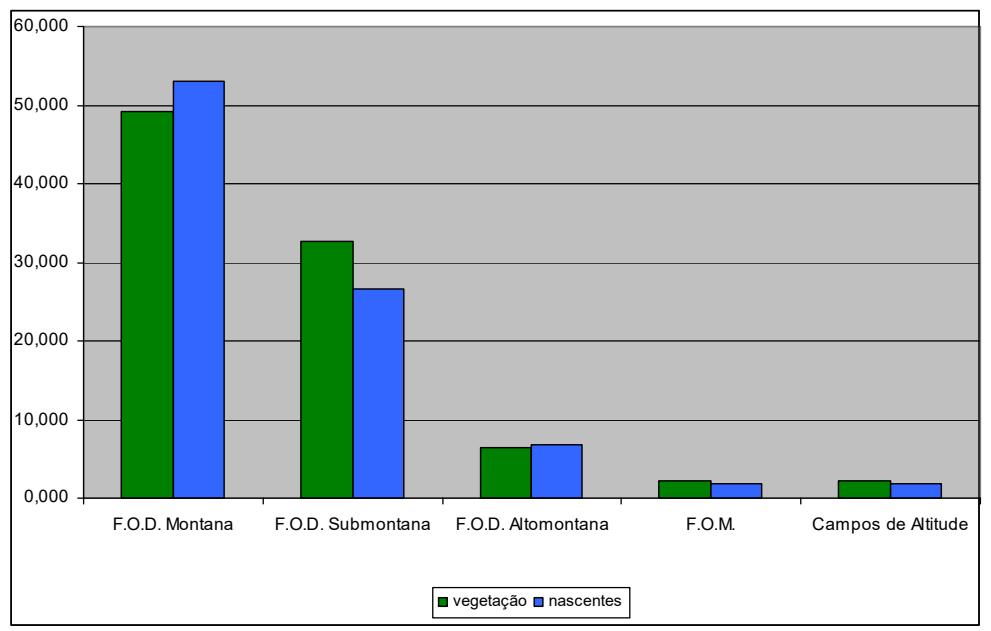

Figura 3: Comparação das tipologias vegetacionais com nascentes na área da AEIT - Marumbi.

As florestas Altomontanas com 250 nascentes $(6,7 \%)$ e os campos de altitude que apresentam apenas 67 nascentes (1,8\%), em escala numérica não são significativos, porém, o controle da água difusa no meio natural é essencial a todo o ambiente. A área de ocorrência da Floresta Ombrófila Mista pode ser considerada como tipologia rara e importante, visto ser a região que sofre maior pressão antrópica. Esta tipologia responde com 6,5\% da área do estudo, possibilitando a ocorrência de 286 nascentes no seu domínio, proporcionalmente representa $7,7 \%$ do total.

\section{DISCUSSÃO}

A análise das relações geológicas, geomorfológicas, hidrológicas e vegetacionais do ambiente ocorrem de forma interligada, proporcionando a compreensão do padrão, da distribuição, da forma, da ordem, da quantidade das unidades analisadas. Wilson (1999) utiliza o termo 'consciliência' para interpretar relações de conjunto e dos fatos interpretados em rede, conseguindo criar uma base de explicação, para os fenômenos que abordam a vida.

Os trabalhos desenvolvidos por Oka-fiori et al. (1987) apresentam resultados sobre a distribuição da drenagem e sua associação ao substrato rochoso. O fator topográfico e a posição das encostas condicionam o comportamento da drenagem, sendo demonstrado pelo fato de que áreas elevadas de origem granítica apresentam fortes declividades de vertentes.

A análise dos resultados do meio biótico segue a premissa de Maturana et al. (2001), de que a dinâmica de qualquer sistema pode ser explicada mostrando as relações entre as suas partes e as regularidades de suas interações, de modo a fazer com que sua organização se torne evidente. No entanto, não é suficiente apenas ser uma unidade funcionando em sua dinâmica interna, é necessário entender em sua circunstância, no entorno, no contexto com o qual o seu funcionamento se conecta.

A compreensão do ciclo hidrológico e suas etapas como evapotranspiração da relação solo e atmosfera, da absorção pela vegetação, escoamento superficial da água que chega ao solo, sua contribuição 
direta para cursos da água ou reservatórios de superfície como lagos e represas, infiltração geológica para formar lençóis subterrâneos, umidade e o clima, já exemplificam a dinâmica complexa dessa unidade de análise.

Dos estudos realizados da dinâmica relacional vegetação e água, Cicco et al. (1988) aponta, na Serra do Mar de São Paulo, que a quantidade de água de chuva que retorna a atmosfera é de $18,23 \%$ e que $80,65 \%$ atinge a superfície do solo e somente $1,12 \%$ da água é escoada por árvores. Segundo os autores, estes dados são compatíveis aos obtidos na Amazônia.

No ecossistema Serra do Mar pode se afirmar que a gravidade é seu principal mecanismo de dissipação, mantendo a relação qualitativa direta com a biota, pois o fluxo de materiais e nutrientes que o sistema hídrico transporta é fundamental para assegurar hábitat e nichos ecológicos. Portanto, qualquer alteração no meio terrestre, mas principalmente próximo as suas nascentes, influirá qualitativamente no ecossistema como um todo. Riccomini et al. (2003) afirma, nas cabeceiras de drenagem a maior energia no sistema hidrológico, sendo que a Serra do Mar apresenta caracterização morfométrica "retilínea" e padrão de drenagem 'dendrítico'. O fluxo hidrológico é a principal variável que determina e limita a distribuição de espécies enfatizando assim o papel dos ecossistemas e seus serviços naturais.

Na Serra do Mar, é necessário considerar além das águas superficiais, as sub-superficiais e a interrelação com o clima, que apresenta médias de pluviosidade acima de 3.400 mm (MANTOVANELLI, 1999). A rede de drenagem da Serra do Mar contribui diretamente para o adequado escoamento, evitando a saturação e gradativamente liberando parte da água retida ou armazenada. Todavia, a proteção de corpos ou sistemas hídricos em unidades de conservação tem sido feita de forma incidental e, quando inseridos, estão de forma parcial (MOYLE et al., 1998).

Esta afirmação é confirmada no estudo. Com o mapeamento e o georreferenciamento das nascentes, percebe-se nas unidades de conservação de manejo restrito (Parque Estadual Pico do Marumbi, da Graciosa, do Pau Oco, Roberto Ribas Lange) inseridas na AEIT, com 12.574 ha ao todo, possuem em seu sistema de proteção 758 nascentes ou uma nascente a cada 16,5 ha. Já as unidades de conservação de manejo sustentável, que são as mais permissivas, considerando a AEIT nesta definição, ocorrem 2.945 nascentes (uma a cada 18,4 por ha) num total de 54.295 hectares (descontando a área de corpos da água).

A análise dos resultados do meio biótico segue a premissa de Maturana et al. (2001), de que a dinâmica de qualquer sistema pode ser explicada mostrando as relações entre as suas partes e as regularidades de suas interações, de modo a fazer com que sua organização se torne evidente. No entanto, não é suficiente apenas ser uma unidade funcionando em sua dinâmica interna, é necessário entender em sua circunstância, no entorno, no contexto com o qual o seu funcionamento se conecta. E quando se trata de seres vivos, a génese e a história jamais são diretamente visíveis, só podem ser reconstruídas de modo fragmentário e interpretativo.

\section{CONCLUSÕES}

A estratégia adotada para o estabelecimento de critérios e procedimentos para conservação da 
natureza in situ está em acordo com a biogeografia ecológica, que relaciona as distribuições dos organismos com fatores bióticos e abióticos, além de buscar o contraponto da visão científica reducionista de espécie ou populações e a consideração de que os hotspots são as áreas prioritárias para a proteção como baliza principal na seleção de sítios naturais protegidos.

A criação de unidades de conservação em ambientes ricos em água e consequentemente em biomassa deve ter como objetivo a proteção de nascentes, com seus padrões de ocorrência e distribuição. A AEIT do Marumbi constitui região estratégica para o fornecimento de recursos hídricos. A média de uma nascente a cada 18 hectares exemplifica esta importância. A adoção de curvas de nível para perímetros de UCs, já possibilitaria a inclusão de maior gama de diferentes aspectos biofísicos que se manifestam geograficamente.

As montanhas de maior relevância, elevação e atributos cênicos pertencem ao domínio do granito e estão protegidos nos perímetros das unidades de conservação integrais, (Conjunto Marumbi, o Pico Paraná e o Morro Sete, entre outros). No entanto, as montanhas e morros de menor elevação que ocorrem no complexo migmatítico granulítico, juntamente aos granitos abaixo dos $1.000 \mathrm{~m}$ s.n.m., apresentam arranjo estrutural que possibilita a ocorrência de $90 \%$ das nascentes mapeadas, mas encontra-se em grande parte exclusas da proteção integral.

Nas cimeiras destes conjuntos montanhosos ocorrem os campos de altitude, que abrangem pouco mais de 1.400 hectares ou $2 \%$ do total da área, e que devem ser protegidos integralmente tanto, pela raridade como no desempenho de serviços naturais: a absorção, a regulação e a distribuição difusa de águas pluviométricas e atmosféricas, tornando-se essencial e estratégico a salva guarda devido a sua relação sistêmica com o ambiente. Os tipos vegetacionais de Floresta Ombrófila Densa Montana e Submontana representam $70 \%$ da AEIT do Marumbi e, são os que apresentam maior ocorrência de nascentes (80\%). Consequentemente, se tornam estratégicos para as comunidades da biota serrana.

O conjunto de unidades de conservação de manejo restrito e uso indireto da área de estudo é representativamente pequeno e não assegura a preservação do patrimônio natural. A AEIT-Marumbi, necessariamente deverá ser categorizada como Área de Proteção Ambiental ainda que esta categoria seja a mais permissiva, ao menos está em acordo a Lei. Sendo ideal, as categorias grupo de proteção integral.

A criação de novas unidades de conservação deve contemplar processos naturais complexos que viabilizem serviços naturais, diversidade de ecossistemas, ambientes raros e frágeis, padrões hídricos, diferentes composições geológicas, variações altitudinais, necessariamente definindo limites através de curvas de nível ou outra modelagem que as atuais linhas geométricas.

Para assegurar a conservação da natureza, deve ser buscada a compreensão de organização do ambiente. As propriedades de um ecossistema ou de um 'organismo', aqui representado pela Serra do Mar, são derivadas da congruência de fatores biofísicos, onde o contexto demonstra que não existe parte isolada que possa assegurar a sua representatividade, mas que a somatória de suas partes representa o 'todo' que desejamos preservar. 


\section{REFERÊNCIAS}

BRETANHA, S. S. F.. Identificação de Nascentes dos Rio dos Sinos na Bacia Hidrográfica dos Sinos, Utilizando Tecnologia SIG. Porto Alegre: UFRGS, 2007.

CICCO, V.; ARCOVA, F. C. S.; SHIMOMICHI, P. Y.; FUJIEDA, M.. Interceptação das Chuvas por Floresta Natural Secundária de Mata Atlântica. Silvicultura, São Paulo, v.20-22, p.25-30, 1988.

CONSTANZA, R.; ARGET, R.; GROOT, R.; FARBERK, S.; GRASSOT, M.; HANNON, B.; LIMBURG, K.; NAEEM, S.; NEILL, R. V.; PARULEO, J.; RASKIN, R. G.; SUTTON, P.; BELT, M. V.. The value of the world's ecosystem services and natural capital. Nature, v.15, p.253-260, 1997.

FELGUEIRAS, C. A.. Introdução ao Geoprocessamento: Modelagem Numérica do Terreno, C.6. 1999.

FIGUEIREDO, W. M. B.; SILVA, J. M. C.; SOUZA, M. A.. Biogeografia e a Conservação da Biodiversidade. In: ROCHA, C. F. D.; BERGALHO, H. G.; SLUYS, M. V.; ALVES, M. A. S.. Biologia da Conservação: essências. São Carlos: RiMa, 2006.

HEILBRON, M.; PEDROSA-SOARES, A. C.; CAMPOS NETO, M. D. C.; SILVA, L. D.; TROUW, R. A. J.; JANASI, V. D. A.. Província mantiqueira. São Paulo: Beca, 2004.

KUMLER, M. P.. An Intensive Comparison of Triangulated Irregular Networks (TINs) and Digital Elevation Models (DEMs), Monograph 45. Cartographica, v.31, n.2, p.1-99, 1994.

MANTOVANELLI, A.. Caracterização da Dinâmica Hídrica e do Material Particulado em Suspensão na Baía de Paranaguá e em Sua Bacia de Drenagem. Dissertação (Mestrado de Geologia) - Universidade Federal do Paraná, Curitiba, 1999.

MATURANA, H. R.; VARELA, F. J.. A árvore do conhecimento: as bases biológicas da compreensão humana. São Paulo: Palas Athena, 2001.

MINEROPAR, D. P. S. M.. Atlas geológico do Estado do Paraná. Curitiba: Mineropar, 2001.
MITTERMEIER, R. A.; GIL, P. R.; MITTERMEIER, C. G.. Megadiversity: Earth's Biologically Wealthiest Nations. México: CEMEX, 1997.

MOYLE, P. B.; RANDALL, P. J.. Evaluating the biotic integrity of watersheds, in Serra Nevada, California. Conservation Biology, v.12, n.6, p.1318-1326, 1998.

PARANÁ. Carta das águas subterrâneas do Paraná: resumo executivo. Brasília: MMA, 2015.

PARANÁ. Mapeamento da Floresta Atlântica do Estado do Paraná. Curitiba: Secretaria de Estado do Meio Ambiente do Paraná, 2002.

PARANÁ. Plano de Manejo: Área de Proteção Ambiental da Serra do Mar. Curitiba: SEMA, 2003.

PARANÁ. Ortofotocartas do Paraná: Cartas topográficas. Curitiba: SEMA, 2005

PIRES, P. T. L.; ZILLI, A. L.; BLUM, C. T.. Atlas da Floresta Atlântica no Paraná. Curitiba: SEMA, 2005.

RICCOMINI, C.; GIANNINI, P. C.; MANCINI, F.. Decifrando a Terra. São Paulo: Oficina de textos, 2003.

SCARANO, F. R.. Struture, function and floristic relationships of plants communities in stressful habitats marginal to the Brazilian Atlantic rainforest. Annals of Botany, v.90, n.4, p.517-524. 2002.

UNESCO. Organização das Nações Unidas para Educação, a Ciência e a Cultura. Patrimônio Mundial no Brasil. Brasília: UNESCO, 2000.

WILSON, E. O.. A Unidade do Conhecimento: consciência. Rio de Janeiro: Campus, 1999.

WRI; UICN; PNUMA. World Recources Institute. The world Conservationa Union. United Nations Environment Programme. A estratégia global da biodiversidade. Curitiba: Fundação O Boticário de Proteção à Natureza, 1992.

A CBPC - Companhia Brasileira de Produção Científica (CNPJ: 11.221.422/0001-03) detém os direitos materiais desta publicação. Os direitos referem-se à publicação do trabalho em qualquer parte do mundo, incluindo os direitos às renovações, expansões e disseminações da contribuição, bem como outros direitos subsidiários. Todos os trabalhos publicados eletronicamente poderão posteriormente ser publicados em coletâneas impressas sob coordenação da Sustenere Publishing, da Companhia Brasileira de Produção Científica e seus parceiros autorizados. Os (as) autores (as) preservam os direitos autorais, mas não têm permissão para a publicação da contribuição em outro meio, impresso ou digital, em português ou em tradução. 